\title{
EVALUATION OF HISTOLOGY AND SEMEN PARAMETERS IN TESTES OF YajF-TREATED ALBINO RATS
}

Agbaje MO., Okoko IE., Duru FIO

Correspondence to Agbaje Michael O. Department of Anatomy, College of Medicine, University of Lagos, Idi-Araba, Mushin, P.M.B. 12003, Lagos, Nigeria. E-mail: dm4real2000@yahoo.com; Telephone: $+2347034324790$

\begin{abstract}
Yaji, also called suya sauce, is a local meat sauce made from complex spices. Some of the effects of its constituents on the liver and brain have been scientifically proven and documented. However, their separate and combined effects on the testes are yet to be fully evaluated. This study aimed at evaluating histological and semen parameters of testes of albino rats treated with Yaji. Thirty adult albino rats were procured and divided into six groups labeled A-F. Group A (control) received feed and water only. Group $B$ (main test group) received aqueous extract of Yajiat $200 \mathrm{mg} / \mathrm{kg}$ body weight, using oral gavage. Groups C-F received $200 \mathrm{mg} / \mathrm{kg}$ body weights of some Yaji constituents - clove, black pepper, groundnut cake and bouillon cubes $(100 \mathrm{mg} / \mathrm{kg}$ body weight) respectively. The experimental period was 56 days. The rats' weights were measured at procurement, weekly, and at end of experiment. Testes weights were also measured and subsequently, gonadosomatic indices of the rats were deduced. Chronic consumption of Yaji was not associated with histological impairment to the testicular architecture. Rather, there was improvement of semen parameters (increased sperm count, motility and percentage normal morphology). However, there was a significant $(p<0.05)$ decrease in body weights and non-significant $(p>0.05)$ increase in gonadosomatic index. Findings from this study suggests that consumption of Yaji has no deleterious effects on the testes within the period of study, considering histological and semen parameters. Further studies may reveal its use in managing obesity and infertility.

Keywords: Gonadosomatic Index, Infertility, Suya Sauce, Sperm Count, Testes, Yaji
\end{abstract}

\section{INTRODUCTION}

From time immemorial, spices have been reportedly used in Nigeria to prepare 'pepper soups', in the diets of post-partum women to aid contraction of the uterus, as food seasoning, as well as in the preparation of a meat sauce called Yaji (Omotayo, 2013). Yaji, also called suya sauce is a local meat sauce made from complex spices and other additives. It is commonly consumed along with a roasted meat called suya (barbecued meat). Although it originated from the Hausa speaking people of Nigeria, its consumption transcends the borders of ethnicity, especially among the elites during relaxation period (Jonathan et al., 2016).

Constituents of Yaji include spices such as clove, Black pepper, ginger, garlic and red pepper; while the other constituents include bouillon cubes (commonly called 'maggi' in Nigeria), salt and groundnut cake (kuli kuli) powder (Festus et al., 2013). Main active ingredient in clove (Syzigium aromaticum) are eugenol and eugenyl acetate (Bensky et al., 2004); in Black pepper (Piper guineense), piperine (Memudu et al., 2015); in ginger (Zingiber officinale.), zingerone and gingerols (Shams-Al-dain, 2015); and in red pepper (Capsicum frutescens), capsaicin (Omolo, 2014).

Somehow, Yaji has become indispensable in the consumption of suya (roasted meat) across Nigeria but there are growing concerns that that an excessive consumption has the capability to induce pancreatic, liver, kidney and brain damage (Nwaopara et al., 2008a; 2010a, b; 2011). However, there exist limited information 
on the histological effects of Yaji and its constituent spices on the male reproductive system, specifically, the testes - male organs that produce the male gametes and the male sexual hormones. This study therefore aimed at evaluating some histological and seminal parameters in testes and epididymis of albino rats treated with Yaji.

\section{MATERIALS AND METHODS}

Adult male albino rats $(n=30)$ weighing within $175-200 \mathrm{~g}$ were procured from Komad Farm Nigeria Limited. They were housed in well ventilated cages and placed in standard animal house of The Department of Anatomy, University of Lagos, with natural photoperiodic condition of twelve hours of light alternating with twelve hours of darkness. The rats were allowed to acclimatize for 21 days before the commencement of the experiment. Weights were measured at procurement, after acclimatization and weekly throughout the duration of the experiment, using an electronic analytical and precision balance (BA210S, $\mathrm{d}=$ $0.0001 \mathrm{~g}$ ) (Satorius GA, Goettingen, Germany).

Clove (dry buds), ginger, black pepper (dry seeds), red pepper (dry fruits), ginger, garlic and african walnut (ehuru, in Igbo) were purchased at Ikotun market in Lagos, Nigeria. The cloves, ginger, black pepper and red pepper were then grounded separately into a powder form with the use of a grinding machine and then kept in an air-tight containers. Measurements were carried out using Electric Balance (Satorius GA, Goettingen, Germany).

After due consultation with 'mai namo' (skewed/roasted meat sellers), spice sellers and previous literature, Yaji was prepared as follows; dry buds of clove $(39 \mathrm{~g})$, ginger powder $(78 \mathrm{~g})$, Black pepper (dry seeds) (30g), garlic (15g), African nutmeg (ehuru in Igbo) $(10 \mathrm{~g})$, red pepper powder $(22 \mathrm{~g})$, table salt $(100 \mathrm{~g})$, bouillon cubes ("maggi") (100g) and groundnut cake (kuli kuli) powder (250g).

Yaji, Black pepper and clove and groundnut cake extracts were prepared similar to method used by Sutyaso et al. (2016), except that the extracts were not evaporated into pasta form. Aqueous extract was prepared by adding $2 \mathrm{~g}$ of the powdered forms of spices to $100 \mathrm{ml}$ of boiling water for 15 minutes. For the Bouillon cube group, $1 \mathrm{~g}$ was dissolved in $100 \mathrm{mls}$ of boiling water and allowed to cool. All test samples were administered after 72 hours of preparation.

Stock solution was prepared according to the guideline given by OECD (Organization of Economic Corporation and Development) as referenced by Erhirhie et al. (2014). It states that the dosage of a drug $(\mathrm{mg})$ should be constituted in an appropriate volume not usually exceeding $10 \mathrm{ml} / \mathrm{kg} \quad(1 \mathrm{ml} / 1000 \mathrm{~g})$ body weight of experimental animals (mice and rats) for nonaqueous solvent in oral route of administration.

\section{Animal Groupings and Administration of Test Samples}

The table below shows a summary of animal groupings and dosage of administration. 
Anatomy Journal of Africa. 2020. Vol 9 (2): 1816 - 1825.

\begin{tabular}{|c|c|c|c|}
\hline GROUP & $\begin{array}{ll}\text { SUBSTANCE } & \text { ADMINISTERED }\end{array}$ & DOSE & $\begin{array}{l}\text { Volume of (oral) } \\
\text { administration }\end{array}$ \\
\hline $\begin{array}{l}\text { A } \\
\text { (Control) }\end{array}$ & Feed \& water & Ad libitum & $1.5 \mathrm{mls}$ \\
\hline B & Yaji + Feed \& water ad lib. & $200 \mathrm{mg} / \mathrm{kg}$ & $1.5 \mathrm{mls}$ \\
\hline C & Clove + Feed \& water ad lib. & $200 \mathrm{mg} / \mathrm{kg}$ & $1.5 \mathrm{mls}$ \\
\hline $\mathrm{D}$ & Black pepper + Feed \& water ad lib. & $200 \mathrm{mg} / \mathrm{kg}$ & $1.5 \mathrm{mls}$ \\
\hline$E$ & $\begin{array}{l}\text { Groundnut cake + Feed \& water ad } \\
\text { lib. }\end{array}$ & $200 \mathrm{mg} / \mathrm{kg}$ & $1.5 \mathrm{mls}$ \\
\hline $\mathrm{F}$ & $\begin{array}{l}\text { Bouillon cube ('maggi') + Feed \& } \\
\text { water ad lib. }\end{array}$ & $100 \mathrm{mg} / \mathrm{kg}$ & $1.5 \mathrm{mls}$ \\
\hline
\end{tabular}

At the end of the experiment, weights of the rats were recorded after which they were sacrificed humanely in conformity with International, National and institutional guidelines for the care of laboratory animals in Biomedical Research. On confirmation of death, the abdominal cavity was opened up through a midline abdominal incision to expose the reproductive organs, and then the testes and epididymes were excised. The testes were weighed with an electronic analytical and precision balance (BA 210S, $d=0.0001$ - Sartorius GA, Goettingen, Germany) and separate weights of the two testes (right and left) of each rat were recorded while their mean weights was later deduced. One of the testes of each animal was fixed in $10 \%$ formaldehyde for histological processing for light microscopy.

Sperm motility, morphology and concentration (sperm count) were deduced from semen minced from the cauda epididymis and viewed with the use of binocular light microscope (X10 and $\mathrm{X} 40)$, after proper incubation at room temperature $(37 \circ \mathrm{C})$. Sperm concentration was estimated using the improved Neubauer's counting chamber (haemocytometer) after proper dilution of the seminal fluid with $1 \mathrm{ml}$ of semen diluting fluid (sodium bicarbonate $5 \mathrm{~g}$, formalin $1 \mathrm{ml}$, distilled water $99.0 \mathrm{ml}$ ). One drop of diluted epididymal fluid was added to the haemocytometer and the number of spermatozoa in the appropriate squares of the haemocytometer was counted under the microscope. The number of spermatozoa per $\mathrm{ml}$ was derived employing the equation; sperm count $=$ number of spermatozoa $\times$ dilution factor $x$ depth factor/number of areas counted.

Sperm motility was determined by counting motile and non-motile sperms in 10 randomly selected fields of the microscope, using X20 objective. Motility was based on rapid or forward progressive, oscillatory and vibrating movements and was expressed as a percentage of total sperm counted.

Abnormal morphology was based on coiled tail, swollen head, pin head, only head and bent neck. Thereafter, the percentages of normal and abnormal shaped sperms were calculated.

Tissue preparation was carried out using standard tissue preparation techniques (fixation, dehydration, impregnation, embedding, sectioning and staining with Haematoxylin and Eosin) as described by David (2014). The micrographs of the relevant stained sections were subsequently taken with the aid of a light microscope (at magnifications X100 and X400).

All data was expressed as mean \pm Standard error mean (SEM). Mean differences were analysed by one-way analysis of variance (ANOVA), using GraphPad Prism, version 5.04 for Windows (GraphPad Software, San Diego California USA). Values of $P<0.05$ was considered to indicate a significant difference. 


\section{Gross and Histological Parameters}

Results of the experiment showed a decrease in body weight of the group that received Yaji when compared to the control group. Conversely, no reduction in body weight was observed in the groups that received clove, groundnut cake (kuli kuli) and bouillon cubes. While an increase in testes weight was observed in groups that received clove, Black

\section{RESULTS}

pepper and groundnut cake, groups that received Yaji and bouillon cubes showed no increase in testes weight. Only groups that received Yaji and clove showed a non significant increase in testis/body weight ratio (Gonadosomatic index, O'), when compared to the control group (Table 2). On comparison of the weight of the left testes with the right, no increase was observed.

Table 2. Changes in Gross Anatomical Parameters of Experimental Animals

\begin{tabular}{|l|l|l|l|l|l|}
\hline $\begin{array}{l}\text { Experimental } \\
\text { Groups }\end{array}$ & $\begin{array}{l}\text { Initial Body } \\
\text { Weight }(\mathrm{g})\end{array}$ & $\begin{array}{l}\text { Final Body } \\
\text { Weight }(\mathrm{g})\end{array}$ & $\begin{array}{l}\text { Body Weight } \\
\text { Difference }(\mathrm{g})\end{array}$ & $\begin{array}{c}\text { Testes } \\
\text { Weight }(\mathrm{g})\end{array}$ & $\begin{array}{l}\text { Testes Wt./Body } \\
\text { Wt. ratio O }\end{array}$ \\
\hline Control & $138.60 \pm 2.00$ & $187.40 \pm 11.50$ & 48.80 & $1.01 \pm 0.20$ & 0.02 \\
\hline Yaji & $158.00 \pm 5.70$ & $191.80 \pm 9.90$ & $33.80 \mathrm{a}$ & $1.26 \pm 0.10$ & $0.04 \mathrm{n}$.s \\
\hline Clove & $184.20 \pm 9.90$ & $222.60 \pm 16.50$ & 38.40 & $1.45 \pm 0.10 \mathrm{~b}$ & $0.04 \mathrm{n} . \mathrm{s}$ \\
\hline B./Pepper & $170.20 \pm 3.60$ & $217.80 \pm 4.70$ & 47.60 & $1.38 \pm 0.10 \mathrm{~b}$ & 0.03 \\
\hline Groundnut Cake & $180.00 \pm 4.60$ & $220.00 \pm 7.00$ & 40.00 & $1.32 \pm 0.10 \mathrm{~b}$ & 0.03 \\
\hline Bouillon Cubes & $140.00 \pm 5.40$ & $189.40 \pm 13.50$ & 49.40 & $1.17 \pm 0.00$ & 0.02 \\
\hline
\end{tabular}

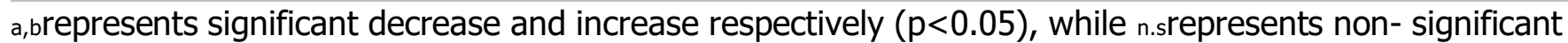
increase $(p>0.05)$, when compared to control values. Values are means \pm S.E.M. $n=5$ in each group.

Figure 1. Graphical representation of changes in right and left testes weights

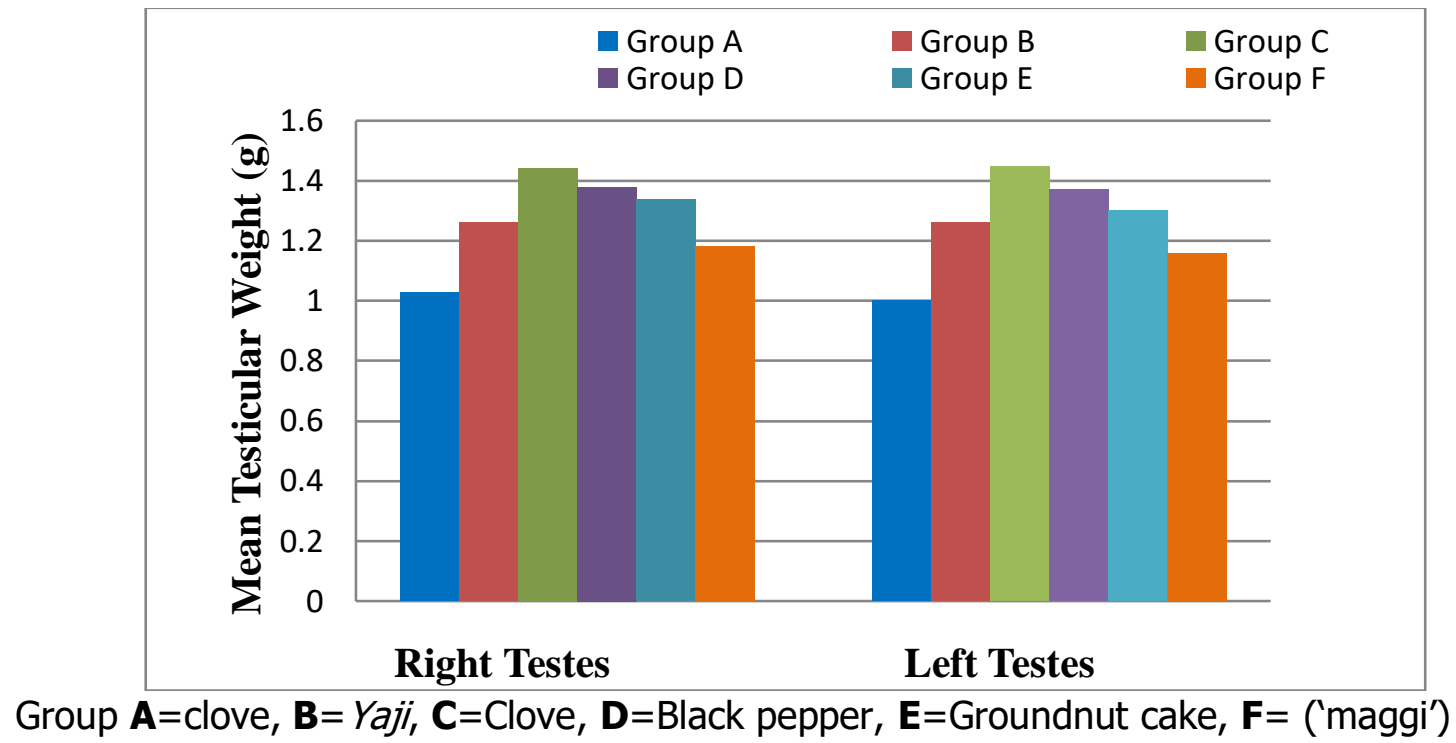

Histological section of the control group showed normal seminiferous epithelium and interstitium. All spermatogenic cell layers are present (Plate 1). Group B (Yaji Group) also 
showed normal seminiferous epithelium with well-stratified and organized cells of the spermatogenic series (Plate 2). Group C (Clove group) showed an outstanding layout when compared to the control group. The seminiferous epithelium presents numerous spermatogenic cells with numerous spermatids. Numerous spermatogonia with constrictions at center suggests a state of rapid cell division. An enlarged interstitium with numerous Leydig cells was also observed (Plate 3). Group D (Black pepper) showed remarkable organization of their seminiferous tubules, far better than what was obtained in the control group. The seminiferous tubules were uniformly spaced and all spermatogenic cells were compactly organized, with spermatogenic all cell layers present. Spermatogonia were seen as giant cells with conspicuous cytoplasm and nucleus. Interstitial spaces also contain numerous Leydig cells. Sertoli cells are conspicuously visible and are well differentiated from the spermatogonia around them (Plate 4). Histological Section of the Group E (Groundnut cake group) animals showed seminiferous tubules of disproportionate widths. Desquamation of the spermatogoneal cells, degeneration of spermatogonia, spermatocytes and spermatids is easily observable. However, the basement membrane was intact in some of the tubules (Plate 5). Group F ('maggi') animals showed seminiferous tubules with segmental tubular atrophy in some parts of the tubules. Other parts appear fairly normal with spermatogenic cells intact. Most seminiferous tubules appear small in diameter with small lumen. Most of the spermatogonia present appear to have lost their cytoplasm, as they could only be seen as a dark mass. Sertoli cells are very scanty and the spermatocytes, degenerated. Furthermore, the basement membrane appears very thin with few myeloid cells seen on it (Plate 6).

\section{Sperm Parameters}

When compared with the control, the groups treated with clove and Black pepper both showed increase in sperm count and motility. The Yaji group showed no increase in sperm count but significant increase in progressive sperm motility. Conversely, the group treated with bouillon cubes ('maggi') showed no increase in sperm count and motility when compared to the control group (Table 2). For sperm morphology, the group that received Yaji and clove showed an increase in normal sperm morphology while the abnormal sperm morphology was significantly low $(p<0.05)$ when compared to the control group (Table 2). The groundnut cake group also showed a significant increase in percentage normal sperm morphology while the group that received Black pepper showed no increase. The group that received Bouillon cubes ('maggi') showed no increase in normal sperm morphology when compared with the control group.

Table 3. Seminal analyses (Sperm count and motility) of experimental groups

\begin{tabular}{llll}
\hline EXPERIMENTAL & SPERM COUNT & TOTAL & \\
GROUPS & $\left(\times 10_{6} / \mathrm{mL}\right)$ & SPERM \\
MOTILITY & MORPHOLOGY
\end{tabular}

(\%)

\begin{tabular}{lllll}
\hline & & & Normal \% & Abnormal \% \\
\hline Control & $156.93 \pm 2.73$ & $61.67 \pm 6.01$ & $77.33 \pm 1.45$ & $22.67 \pm 1.45$ \\
\hline Yaji & $162.23 \pm 0.62$ n.s & $94.33 \pm 2.33 \mathrm{~b}$ & $89.67 \pm 0.89 \mathrm{a}$ & $10.33 \pm 0.88 \mathrm{c}$ \\
\hline Clove & $174.07 \pm 1.53_{\mathrm{a}}$ & $95.0 \pm 0.00 \mathrm{~b}$ & $94.67 \pm 0.67 \mathrm{~b}$ & $5.333 \pm 0.67 \mathrm{~d}$ \\
\hline Black pepper & $174.27 \pm 2.31_{\mathrm{a}}$ & $92.67 \pm 2.96 \mathrm{~b}$ & $89.00 \pm 4.04 \mathrm{n} . \mathrm{s}$ & $11.00 \pm 4.04 \mathrm{n} . \mathrm{s}$ \\
\hline Groundnut Cake & $158.90 \pm 4.68$ & $93.33 \pm 1.86 \mathrm{~b}$ & $93.33 \pm 1.67 \mathrm{a}$ & $6.667 \pm 1.67 \mathrm{~d}$ \\
\hline Bouillon cubes ('maggi') & $148.57 \pm 4.75$ n.s & $52.33 \pm 2.40$ n.s & $74.67 \pm 2.91_{\mathrm{n} . \mathrm{s}}$ & $25.33 \pm 2.90_{\mathrm{n} . \mathrm{s}}$ \\
\hline
\end{tabular}


$a, b r e p r e s e n t s$ significant increase at $p<0.05$ and $p<0.01$ respectively, c,drepresents significant decrease at $p<0.05$ and $p<0.01$ respectively. n.srepresents non-significant decrease $(p>0.05)$ while n.srepresents nonsignificant increase $(p>0.05)$, when compared to control values. Values are expressed in means \pm S.E.M. $\mathrm{n}=5$ in each group.

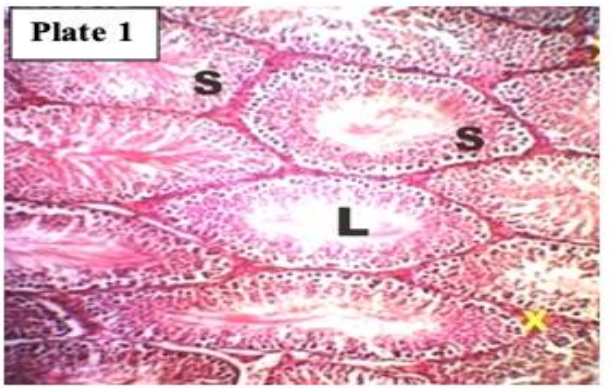

Cross section of the testis of the Control Group. H\&E $\mathrm{X} 100 . \mathbf{S}=$ seminiferous epithelium, $\mathbf{z}=$ lumen of seminiferous tubule. $\mathbf{X}=$ Testicular Interstitium

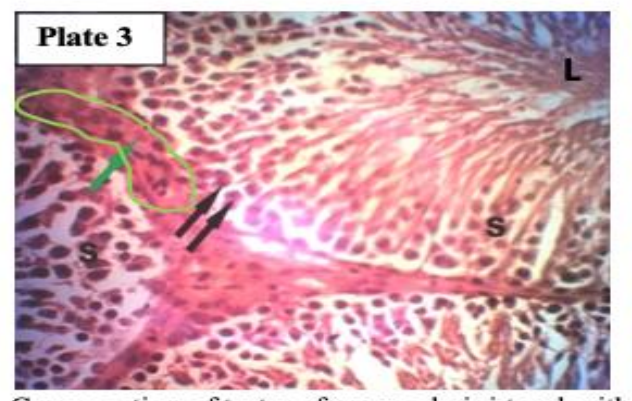

Cross section of testes of group administered with clove at $200 \mathrm{mg} / \mathrm{kg}$. H\&E X400. $\mathbf{S}=$ seminiferous epithelium, $\mathbf{L}=$ =lumen of seminiferous tubule, $\mathbf{x}=$ testicular interstitium, $\longrightarrow=$ Constricted cytoplasm $\rightleftharpoons=$ Enlarged interstitium

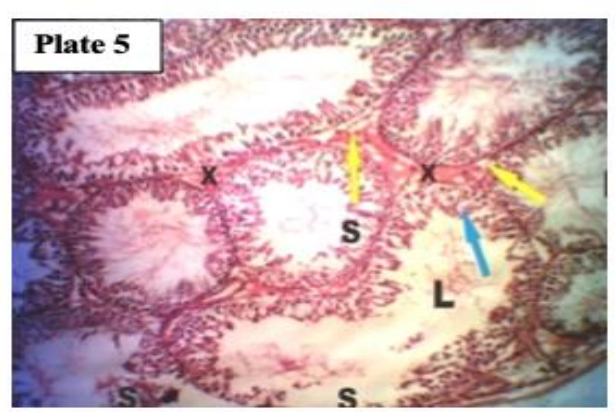
Cross section of the testis of group administered with Cross Section of the testis of group administered with
groundnut cake at $200 \mathrm{mg} / \mathrm{kg}$. H\&E X100.
Bouillon cube ('maggi') at $100 \mathrm{mg} / \mathrm{kg}$. H\&E X100. $\mathbf{s}$-seminiferous epithelium, $\mathbf{Z}$-lumen of seminiferous $\mathbf{S}=$ seminiferous epithelium, $\mathbf{L}=$ lumen of seminiferous

tubule, $\mathbf{x}$-testicular interstitium $\Rightarrow=$ Vaçolation tubule, $\mathbf{x}=$ =testicular interstitium, $\mathbf{v}=$ blood vessel of interstitium, $\Rightarrow=$ Vacuolation in epithelium

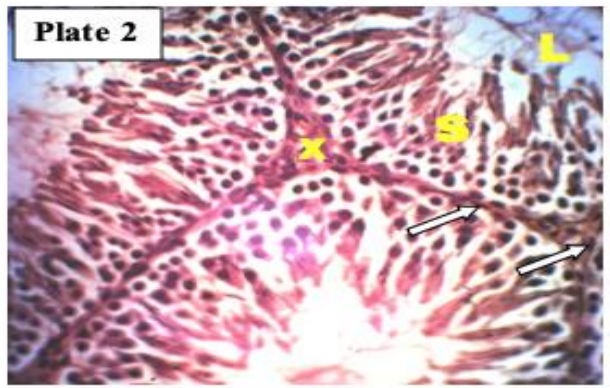

Cross section of testis of the group administered with $Y a j i$ at $200 \mathrm{mg} / \mathrm{kg}$. H\&E X400. $\mathbf{s}=$ seminiferous epithelium, $\mathbf{L}=$ lumen of seminiferous tubule,

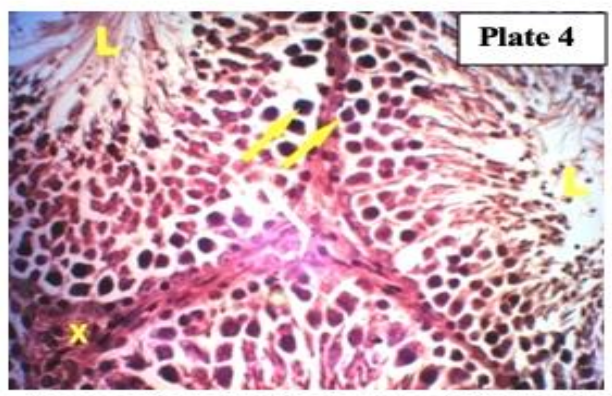

Cross section of testis of group administered with B lack pepper at $200 \mathrm{mg} / \mathrm{kg}$. H\&E X 400 .

$\mathbf{I}=$ lumen of seminiferous tubule, $\mathbf{x}=$ testicular interstitium $\gg=$ Spermatogonium with dense cytoplasm

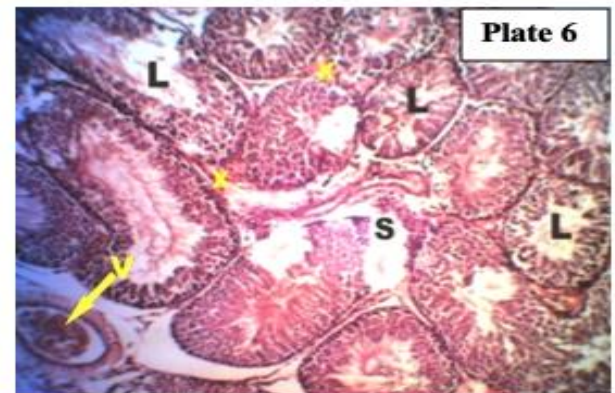

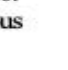


Anatomy Journal of Africa. 2020. Vol 9 (2): 1816 - 1825.

\section{DISCUSSION}

The significant decrease in weight observed in the Yaji group is consistent with previous researches (Agbaje et al., 2009; Akpamu et al., 2014). This weight loss in the Yaji group, and also the Clove group, may be as a result of the high rate of metabolism elicited by eugenol, a component of both substrates, as reported by Oyewole et al. (2007). Weight loss in the groundnut cake group may be due to its high dietary fiber content which has been directly linked to weight loss and low body mass index (BMI). Consequently, weight loss observed in the Yajigroup may be due to the fact that groundnut cake occupies its major mass of constituent, and not because of adverse spermatogenic activities. Although non significant, the slight weight gain recorded in the group administered with bouillon cubes is due to the presence of Monosodium glutamate (MSG) an active component present in it. It has been proven that MSG improves palatability of meals and influences appetite positively (Hermanussen et al., 2005; Bellisle, 2008; He et al., 2008; Agbaje et al., 2009; Carter et al., 2011). Moreover, the high feeding rate observed in the group administered with bouillon cubes further shows that the recorded increase in body weight cannot be attributed to spermatogenic activities.

The non-significant increase in testes weights of the Yaji group alongside the significant increase in the Clove, Black pepper may be due to the abundant presence of zinc in the substrates. Zinc has been reported to be utilized for spermatogenic cell formation and reactions within the testes. A non-increase in the gonadosomatic index indicates that the increase in body weight recorded may not be connected to androgenic activities of the testes.

With respect to the adverse histological derangement observed in the Groundnut cake group, a substrate which is the major constituent of Yaji, the normal histoarchitecture observed in Yaji group may be due to the ameliorating potentials of Clove and Black pepper which are also major spice constituents of Yaji. Clove and Black pepper have been proven to possess high antioxidant potential and abundant ions such as zinc, which is essential for the production of testosterone and also to prevent testicular degeneration consequent of oxidative stress due to actions of their active ingredients, eugenol and piperine, respectively (Shyamala et al., 2003; Sutyarso et al., 2014). However, the positive result of this current study on the Yaji group differs from findings of Ukoha et al. (2014) which reported damage to the seminiferous tubules; reduction of viable sperm; and destruction of the structural arrangement of the sperm and Leydig cells. This is likely due to the higher dose of Yaji $(15 \mathrm{~g}$, mixed daily with their feed ration) administered to the animals in the research, hence validating the dosage ( $200 \mathrm{mg} / \mathrm{kg}$ body weight) utilized in this study. The remarkable histological layout observed in the seminiferous tubules of Black pepper group is the best in all test groups. This is due to the presence of piperine, the active ingredient in the Black pepper. Piperine possesses testosterone $5 \alpha$-reductase inhibitory effect which causes testosterone level to remain high; hence a high libido. Findings of Vijayakuma and Nalini (2006) confirm this. The testicular derangement of the groundnut cake group is consistent with previous studies (Hanis et al., 1989; Veaute et al., 2007; Chavarro et al., 2014). Conversion of the fat in peanuts to trans fatty acids in roasted peanuts ( $k u l i$ kuli) gives rise to low density lipoproteins (LDL) which poses negative negative consequence on the testis and serum testosterone in men, hence low sperm count and low testes weight. The cellular atrophy seen in the group administered with bouillon cubes ('maggi') is consistent with previous work on monosodium glutamate, the active component of 'maggi'. A previous study by Nwaopara et al. (2017) has associated monosodium glutamate of white 'maggi' (one of the constituents of Yaji) with oligozoospermia and increased abnormal sperm morphology. The above fact corroborates the findings of this research - that monosodium glutamate may be a major contributor to the severe destruction of the arrangement of the testicular architecture as observed in the group $\mathrm{F}$ ('maggi') in the present study. 
The outstanding values of seminal parameters observed in the Clove and Black pepper groups is due to their possession of abundant nutrients such as protein, calcium, zinc, manganese, phosphorus, vitamins (B6, B12, C, A, E, etc.), etc. Among these nutrients, zinc and vitamin $A$ have been reported to play great roles in spermatogenesis (Cathryn and Griswold, 2010; Parle and Khanna, 2011; Sutyarso et al., 2016). While zinc is utilized for spermatogenic cell formation and reactions within the testes, vitamin $A$ helps in the mediation of the production of testosterone by the Leydig cells, in response to $\mathrm{LH}$ released from the pituitary gland. Therefore, consequent of the presence of Clove and Black pepper in Yajimixture, the increase in sperm concentration, total sperm motility and normal sperm morphology can also be attributed to the presence of zinc and vitamin A in it. The presence of spices such as clove, black pepper and ginger in the groundnut cake accounts for the significant increase in total sperm motility and normal sperm morphology of the groundnut cake group. The decrease in sperm concentration, total sperm motility and normal sperm morphology in the bouillon cake group agrees with a previous study by Nwaopara et al. (2017) who also associated monosodium glutamate present in bouillon cubes with oligozoospermia and increased abnormal sperm morphology. However, the decrease was nonsignificant $(p>0.05)$, probably due to the low dose administered (Table 2).

In conclusion, following the period of 56-day administration, Yaji caused significant weight loss, increased sperm count, normal testicular architecture and increase in percentage normal sperm morphology.
The positive attributes of Yaji was due to the presence of the spices (limited mainly to clove and Black pepper in this study) in it. The spices helped to attenuate the deleterious effects posed by groundnut cake and the additive 'maggi', thereby presenting no threat to testicular function of the Yaji group. Inferentially, the spices, clove and Black pepper, present in Yaji enhances positive testicular functions while the additives in it, groundnut cake and bouillon cubes ('maggi') pose mild deleterious effects on the testes.

However, it should be noted that if the dose of administration is increased from what was used in this study $(200 \mathrm{mg} / \mathrm{kg}$ body weight), the additives will consequently be increased also. Therefore, oxidative stress may ensue with consequent testicular impairments. This has been shown in other studies, when higher doses presented deleterious effects on the liver, kidney, and even the testes (Nwaopara et al., 2007a; Festus et al., 2013).

Consequently, Yaji can be said to possess positive androgenic potentials, with respect to histological and spermatogenic parameters, and presents no deleterious effect on the testicular structure, at a regulated dose (200mg/kg.b.w). Invariably, consumption of Yaji will be of reproductive benefits, if dosage is kept at the barest minimum.

More research should be carried out on human subjects on the use of Yaji to manage obesity and infertility. This would be a landmark achievement, especially in Nigeria, since it is readily available, unlike most obesity and infertility management drugs that are either not produced in Nigeria, expensive or not easy to procure.

ACKNOWLEDGEMENTS: The authors are immensely grateful for the technical assistance provided by Dr. J. Medubi (Anatomy Department, University of Lagos, Idi-Araba, Lagos), Mr. O. Mike (Laboratory 
Anatomy Journal of Africa. 2020. Vol 9 (2): 1816 - 1825.

Technologist, Physiology Department, University of Lagos, Idi-Araba, Lagos) and Mr. J.A. Oguntola (Laboratory Technologist, Anatomy Department, Lagos State University, Ikeja, Lagos).

CONFLICT OF INTEREST: The authors declare no conflicts of interest

\section{REFERENCES}

1. Agbaje EO, Adeneye AA, Daramola AO. 2009. Biochemical and toxicological studies of aqueous extract of Syzigium aromaticum in rodents. Afr. J. Tradit. Complement Altern. Med. 6(3): 241254.

2. Akpamu U, Nwaopara AO, Izunya AM. 2014. A comparative study on weight changes in rats fed with a diet containing Yaji, Yaji additives and Yajissices. Biology and Medicine; 3 (5): 6-15.

3. American Physiological Society. 2002. Guiding principles for research involving animals and human beings. Regul. Integr. Comp. Physiol. 283:281-283.

4. Bellisle F. 2008. Experimental studies of food choices and palatability responses in European subjects exposed to the umami taste. Asia Pacific Journal of Clinical Nutrition, 17(S1), 376-379.

5. Benski D, Clavey S, Stoger E, Gamble A. 2004. Chinese herbal medicine Materia medica (3rd ed.). Seattle: Eastland press, Inc.

6. Carter BE, Monsivais P, Perrigue, MM, Drewnowski A. 2011. Supplementing chicken broth with monosodium glutamate reduces hunger and desire to snack but does not affect energy intake in women. British Journal of Nutrition, 106(09), 1441- 1448.

7. Chavarro JE, Mínguez-Alarcón L, Mendiola J, Cutillas-Tolín A, López-Espín JJ, Torres-Cantero AM. 2014. Trans fatty acid intake is inversely related to total sperm count in young healthy men. $J$. Hum. Reprod. 29(3):429-40.

8. David KA, Florian T, Unger PU, Hartmut L, Moore M, Carolyn C, Björn N, Arnulf D, Andreas W, Carsten Z. 2014. Surgical procedures and postsurgical tissue processing significantly affect expression of genes and EGFR-pathway proteins in colorectal cancer tissue. Oncotarget. 5(22): 11017-11028.

9. Erhirhie EO, Emudainohwo JOT, Edafe EU. 2013. Effects of Vernonia amygdalina and Ocimum gratissimum combined leave extracts on blood glucose and biochemical parameters in alloxan induced diabetic rats. Continental J. Pharmacology and Toxicology Research. 6 (2): 13-21.

10. Festus OO, Agbo GE, Ihongbe JC, Osadolor HB, Okodua MA, Nwaopara AO, Unuabonah FH. 2013. Assessment of the effect of Yaji on the liver profile of Adult Albino Wistar Rats. Asian J. Biol. Life Sci., Vol-2 | Issue-3. ISSN: 2384-681X.

11. Hanis T, Zidek V, Sachova J, Deyl Z. 1989. Effects of dietary trans-fatty acids on reproductive performance of Wistar rats. British Journal Of Nutrition 61(3):519-29.

12. He K, Zhao L, Daviglus ML, Dyer AR., Van Horn L., Garside D, Zhu L, Dongshuang Guo, Yangfeng Wu, Beifan Zhou, Jeremiah Stamler. 2008. Association of monosodium glutamate intake with overweight in Chinese adults: the INTERMAP Study. Obesity (Silver Spring). 16(8): 1875-1880.

13. Hermanussen M, Sunder M, Voigt M, Salazar V, Tresguerres JAF. 2005. Obesity, voracity and short stature: the impact of glutamate on the regulation of apetite. Eur J. Clin. Nutr. (advance online publication 30.8.2005).

14. Jonathan SG, Adeniyi MA, Asemoloye MD. 2016. Fungal Biodeterioration, Aflatoxin Contamination, and Nutrient Value of (Suya Spices). Scientifica Volume 2016, Article ID 4602036. DOI.org/10.1155/2016/4602036. 
15. Memudu AE, Akinrinade, ID, Ogundele OM, Dare BJ. 2015. Effects of crude extract of Dry fruits of Piper guineense on male fertility parameters of Adult Sprague Dawley rats. Eur. J. Med. Plants, 5(3): $297-303$.

16. Nwaopara AO, Odike MAC, Ikhuoriah TA, Anyanwu LC. 2007a. Potential health hazards in Yaji: The complex suya meat sauce. Medilink J., 8 (74): 34-38.

17. Nwaopara AO, Odike MC, Inegbenebor U, Adoye MI. 2007b. The Combined effects of excessive consumption of ginger, clove, red pepper and black pepper on the histology of the liver. Pakistan Journal of Nutrition, 6(6): 524-527.

18. Nwaopara AO, Anibeze CP, Akpuaka FC. 2010a. Induced Histological Features of HypoxiaIschaemia in the brain of rats fed with diet containing Yaji: the complex nigerian meat sauce. Research Journal of Applied Sciences, Engineering and Technology, 2(1): $67-72$.

19. Omolo MA, Wong Z, Mergen AK, Hastings JC, Le NC. 2014. Antimicrobial properties of chili peppers. J. Infect Dis Ther.; 2:145.

20. Omotayo OA, Oladejo T, Keshinro OO. 2013. Evaluation of micronutrient potentials of seven commonly consumed indigenous spices from Nigeria. Am. J. Food. Nutr, 3(3): 122-126.

21. Oyewole IZ, Magaji OA, Awoyinka A. 2007. Biochemical and toxicological studies of aqueous extract of Tithonia diversifolia (hemsl.) leaves in wistar albino rats. J. Med. Plants Res., 1(2): 030033.

22. Shyamala D, Mallika JC. 2003. Potent antiulcerogenic activity of Cissus quadrangularis on aspirin induced gastric ulcer by its antioxidative mechanism. J. Clin. Biochem. Nutr. 34, 43-47.

23. Sutyarso M, Kanedi M. 2016. The Effect of Fruit Extracts of Black Pepper on the Fertility Potential of Male Albino Mice. American Journal of Medical and Biological Research, Vol. 4, No. 1, 1-4.

24. Ukoha UU, Egwu OA, Dimkpa U, Maduka SO, Okafor JI, Ndukwe GU, Ogonnadi K. 2016. Histological and Weight Changes in Testes of Male Albino Rats Fed with Diets Containing Yaji (A Local Meat Sauce). International Journal of Health Sciences and Research. Vol.4; Issue: 8. ISSN: 2249-9571.

25. Veaute C, Florencia MA, Racca A, Bailat AS. 2007. Effects of Isometeric Fatty Acids on Reproductive Parameters in Mice. American Journal of Reproductive Immunology. 58(6):487-96.

26. Vijayakumar RS, Nalini N. 2006. Piperine, an active principle from Piper nigrum, modulates hormonal and apo lipoprotein profiles in hyperlipidemic rats. $J$ Basic Clin Physiol Pharmacol. 17(2):71-86. 